\title{
Análise de Práticas Pedagógicas e avaliativas: contribuições para a Política de Formação Docente
}

Cremilda Barreto Couto

\section{Resumo}

O objetivo deste artigo é apresentar parte da pesquisa amostral intitulada "Análise de Práticas Pedagógicas e avaliativas: contribuições para a política de Formação Docente" realizada no ano de 2017, em 04 salas de aula de $5^{\circ} \mathrm{S}$ anos, de 04 escolas com bons resultados no IDEB, no município de MacaéRJ. Deu-se a partir de um olhar apurado sobre a metodologia dos professores e suas práticas avaliativas. A metodologia da pesquisa foi de cunho Qualitativo Bibliográfica e de campo através de observações e aplicação de questionários. A pesquisa contou com a participação de o8 alunos/pesquisadores da licenciatura em Matemática de uma faculdade pública. O tema da investigação justifica-se, na defesa da ideia de que a atuação do professor em sala de aula é um dos elementos que deve ser considerado ao olhar-se o desempenho da escola. Como fundamentação teórica utilizou-se os conceitos de campo e de habitus, postos por Pierre Bourdieu (2003, 2009) e outros autores que discutem a avaliação. Os resultados mostraram que o lugar ocupado pela avaliação não é igual em todas as escolas, alguns professores valorizam a heterogeneidade da sala de aula e subjetividade dos alunos, enquanto outros dão centralidade ao treinamento para as avaliações externas. Considerou-se que se precisa ouvir os professores acerca de suas necessidades cotidianas, a fim de se pensar junto de que maneira a formação continuada pode auxiliar mais efetivamente na resolução dos problemas inerentes à sala de aula.

Palavras-chave: Avaliação. Prática Pedagógica. Política de Formação Docente. 


\section{Analysis of pedagogical and evaluative practices: contributions to education policy}

Cremilda Barreto Couto

Abstract

The purpose of this article is to present part of the sample research entitled "Analysis of Pedagogical and evaluative Practices: Contributions to the Policy of Teacher Education" held in 2017, in 4 classrooms of 5 years, from 04 schools with good results in IDEB, in the municipality of Macaé-RJ. It was based on an accurate look at the methodology of teachers and their evaluation practices. The methodology of the research was Qualitative Bibliographic and field through observations and application of questionnaires. The research had the participation of o8 students / researchers of the degree in Mathematics of the public Faculty. The research theme is justified, in defense of the idea that the teacher's performance in the classroom is one of the elements that should be considered when looking at the performance of the school. As a theoretical basis, we used the concepts of field and habitus, put by Pierre Bourdieu (2003, 2009) and other authors who discuss the evaluation. The results showed that the place occupied by the evaluation is not the same in all the schools, some teachers value the heterogeneity of the classroom and subjectivity of the students, while others give centrality to the training for the external evaluations. It was considered that teachers need to be heard about their daily needs in order to think about how continuing education can more effectively help solve the problems inherent in the classroom.

Keywords: Evaluation. Pedagogical Practice. Teacher Training Policy. 


\section{Introdução}

A pesquisa intitulada "Análise de Práticas Pedagógicas e avaliativas: contribuições para a política de Formação Docente” realizada no ano de 2017, se deu a partir da atividade de formação/pesquisa desenvolvida no Centro de Formação Professora Carolina Garcia - CFCG na cidade de Macaé - Estado do Rio de Janeiro.

O CFCG inicia suas atividades de formação continuada de professores, como Centro, no dia 13 de novembro de 2015. Anteriormente a formação continuada já acontecia através de estruturação em coordenações. No período de realização da pesquisa o CFCG trabalhava com uma perspectiva de formação continuada através de cursos de curta e média duração, simpósios, seminários, além de enxergar na pesquisa um possível elemento desencadeador de formulação de Política Pública.

O objetivo da pesquisa foi observar a prática dos professores, em escolas com bom resultado no Índice de Desenvolvimento da Educação Básica - IDEB da Rede Municipal de Macaé/RJ, com olhar apurado sobre a metodologia na sala de aula e a avaliação. Trabalhou-se com dados amostrais, considerando possíveis contribuições para a política de formação docente da Secretaria Municipal de Educação de Macaé e do Centro de Formação Professora Carolina Garcia.

A pesquisa contou com a participação voluntária de 08 alunos34 da licenciatura em Matemática de uma Faculdade Pública. Promovendo interlocução com o que é teorizado no espaço acadêmico e a prática onde se pretende atuar. Acredita-se que a investigação promoveu uma rede conectiva entre o ensino e a pesquisa e favoreceu uma aprendizagem significativa para a vivência dos alunos da graduação no ambiente escolar.

O tema da investigação justifica-se, na defesa da ideia de que a atuação do professor em sala de aula é um dos elementos que deve ser considerado ao olhar-se o desempenho da escola. Além disto, a estruturação de um trabalho de formação, passa pela compreensão daquilo que se faz necessário para melhoria da educação e uma das formas de entender o cotidiano da escola, é estar nele. Além disso, apesar da temática da avaliação não ser nova, continua a inquietar àqueles que se encontram na sala de aula, os que estão em espaço de gestão e pesquisadores da área.

O ponto de partida para realização da pesquisa foi a observação dos dados do IDEB utilizados pelo Município de Macaé como uma representação de "qualidade”. Como em outras partes do Brasil a Política de Avaliação Externa que vem ganhando força nas redes de ensino, com maior demarcação nos anos 1990. Machado e Alavarse (2014) resgatam o histórico da avaliação externa no Brasil retomando a estruturação do Sistema de Avaliação da Educação

34 Os alunos participantes da pesquisa, estiveram matriculados na disciplina de Política de Gestão e Organização da Educação Nacional, da professora Cremilda Barreto Couto no ano de realização da pesquisa. 
Básica (SAEB) em 1995, apontando algumas mudanças, nas quais a primeira compreendeu o "levantamento" de dados socioeconômicos, culturais e sobre hábitos de estudo dos avaliados e a segunda alteração foi a interação da metodologia de medir o desempenho dos alunos ao longo do tempo. De acordo com o MEC, o Saeb e a Avaliação Nacional do Rendimento Escolar (Anresc) são exames complementares. O Ideb (Índice de Desenvolvimento da Educação Básica, foi criado, de acordo com o presidente do Inep em 2007, para ser indicador de qualidade educacional, o governo projeta metas a serem alcançadas.

Com base nisto, para desenvolvimento deste estudo utilizou-se a Pesquisa Qualitativa, Básica, de cunho bibliográfico, destinando-se espaços para estudos reflexivos voltados para a formação metodológica dos alunos-pesquisadores envolvidos. Na sequência trabalhou-se com a coleta de dados em 4 escolas do Ensino Fundamental I de Macaé/RJ, especificamente nos $5^{\circ}$ s anos, por ser o período de realização da Prova Brasil. A escolha dessas escolas deu-se a partir da nota do Índice de Desenvolvimento Educacional - IDEB do ano de 2015, comparada com a meta estabelecida para o mesmo ano. Dentro deste viés essas escolas foram analisadas contextualmente a partir de um olhar mais apurado para a prática pedagógica e avaliativa do professor. Considerou-se relevante destacar alguns aspectos de 04 salas de aula, da rede municipal de ensino de Macaé, que pudessem vir a contribuir com outras unidades escolares.

$\mathrm{Na}$ escolha dos espaços onde se daria a investigação, desconsiderou-se as escolas localizadas na região serrana, devido ao tempo de acesso, o que seria desfavorável para os alunos/pesquisadores. Selecionou-se escolas que estivessem em localidades de periferia e de bairros com população de maior poder aquisitivo, para que as diferenças socioeconômicas dessem maior credibilidade aos dados.

Estes, foram coletados através de observação não participante e para melhor direcionamento, considerou-se algumas categorias para observação na sala de aula: identificação do professor, didática e metodologia utilizada, avaliação e mediação junto aos alunos. A estrutura física da sala de aula e da escola e outras questões apontadas pelo campo, foram consideradas para melhor compreensão dos dados.

Além da observação não participante foi aplicado questionário semiestruturado aos professores das turmas através do eixo I - Da Identificação; Eixo II - Didática e metodologia em sala de aula; Eixo III Avaliação e mediação junto aos alunos e uma questão discursiva quanto as dificuldades de aprendizagem dos alunos.

Os instrumentos considerados adequados à investigação foram à observação não participante e a entrevista, elementos inseparáveis, no entender de Beaud e Weber, já que,

a entrevista encontra-se apoiada em outros recursos cuja função é complementar informações e ampliar os ângulos de observação e a condição de produção dos dados. Não havendo separação entre as duas, uma vez que é no quadro da pesquisa que se define o que cabe a cada uma delas. (in. ZAGO, CARVALHO E VILELA, 2003, p.298). 
Todo o material observado foi registrado em diários de bordo, já que no entender de Tura (2003, p.191) as anotações são realizadas primordialmente como forma de entendimento do que se passa no campo de investigação, numa tentativa de elaboração pessoal do que se observa ou como uma estratégia de reunir questões e estabelecer o que se irá mais atentamente focalizar e os novos procedimentos que serão adotados.

As escolas participantes da pesquisa, são encontradas com os melhores índices no IDEB, identificadas a partir das letras do alfabeto, objetivando preservá-las: Escola A (média ideb 5.6); escola B (média ideb 5.9); Escola C (média ideb 6.5) e escola D (média ideb 6.0).

O tempo de duração da pesquisa foi de 07 meses organizados da seguinte forma: apresentação do projeto às coordenações da Secretaria Municipal de Educação - SEMED e do CFCG; encontros de fundamentos metodológicos com os alunos/pesquisadores; definição das escolas, turmas, turnos; observações; aplicação dos questionários e escrita do texto.

Para fundamentação teórica deste estudo utilizou-se os conceitos de campo e de habitus, postos por Pierre Bourdieu (2003, 2009), considerando as linguagens próprias da educação e interlocução entre os pares. Além de destacar o papel ativo dos agentes na pesquisa, neste caso os professores. Sendo o homem, na perspectiva do autor, um ser social, entende-se como possível a mudança (interna) e da sociedade (externa), ou seja, através da ação direta deste, como agente, sobre a sociedade. Sendo assim, traz-se para o cenário de discussão o professor, por considerá-lo ativo no processo de construção do conhecimento e de ações que interferem no ambiente social. Considerou-se importante pensar a partir do conceito de campo, tendo em vista a contribuição deste na compreensão das particularidades e complexidades existentes no campo educacional. Na teoria bourdieusiana existem campos, enquanto espaços sociais (religioso, artístico, dentre outros) que se caracterizam como universos relativamente autônomos, espaços de jogo e disputas com características e regras próprias. As pessoas envolvidas nesse jogo possuem por esse motivo, interesses específicos, que são definidos pela lógica do jogo e não pelos mandantes (Bourdieu, 2009, pg. 200). Compreende-se, portanto, que nessa concepção de campo há dimensões de poder, desejos e que se pensando em um jogo, estratégias precisam ser estabelecidas, como também se dá no campo da educação. Apesar de Bourdieu não se referir especificamente ao campo da educação, tomou-se como referência, compreendendo que as identificações do conceito perpassam também o campo da educação. Pressupõe-se, então, que conhecendo melhor o campo da educação e da escola, também se faz conhecida a prática do professor, que se dá no espaço micro do campo.

Com base em Bourdieu (2003), utilizou-se o conceito de habitus por entender que o professor vai incorporando conhecimento aos esquemas já constituídos que contribuirão para a sua formação como indivíduo e na estruturação do grupo em que está inserido. Portanto, o habitus do professor adquirido ao longo de suas vivências e experiências interferirão na forma 
como a sua prática pedagógica e sua concepção ante à avaliação se dão. Grenfell (2018, p. 75) considera o conceito de "habitus a partir de um enigma experencial [...]". Ainda, explica que "No contexto da experiência, nós muitas vezes sentimos que somos agentes livres, mas baseamos as decisões cotidianas em pressuposições sobre o caráter, comportamento e atitudes previsíveis de outras pessoas (GRENFELL, 2018, p. 75). Ou seja, o habitus individual do professor sofre influência, ao mesmo tempo em que interfere nas interações junto aos pares, através da troca de experiências (coletivo).

Considerando nesta reflexão a centralidade dada a prática do professor, as possíveis contribuições que a observação dessa prática pode trazer, apoiou-se nas reflexões postas por Tardif (2000) ao ampliar a importância da pesquisa neste processo.

[...] se os pesquisadores universitários querem estudar os saberes profissionais da área do ensino, devem sair de seus laboratórios, sair de seus gabinetes na universidade, largar seus computadores, largar seus livros e os livros escritos por seus colegas que definem a natureza do ensino, os grandes valores educativos ou as leis da aprendizagem, e ir diretamente aos lugares onde os profissionais do ensino trabalham, para ver como eles pensam e falam, como trabalham na sala de aula, como transformam programas escolares para torná-los efetivos, como interagem com os pais dos alunos, com seus colegas etc. (p. 13)

Portanto, a realização desta pesquisa não tinha como pressuposto apenas tratar o professor como um objeto de pesquisa, mas numa interlocução com ele, tentar contribuir com um olhar mais apurado sobre as complexidades que se dão na escola. Acredita-se, enquanto pesquisador, que a universidade tem compromisso não só intelectual como também social com a melhoria da qualidade do ensino.

O objetivo deste artigo é apresentar parte da pesquisa amostral realizada em 04 salas de aula de $5^{\circ}$ s anos, de 04 escolas com bons resultados no IDEB, no município de Macaé/RJ, a partir de um olhar apurado sobre a metodologia dos professores em sala de aula e suas práticas avaliativas. Busca também contribuir com a elaboração de políticas públicas para a formação docente.

Este estrutura-se, inicialmente a partir de fundamentos teóricos. Sequenciado por estudo reflexivo dos elementos apontados nas observações nas salas de aula e questionários aplicados junto aos professores. Enquanto as considerações finais trazem outros aspectos tidos como relevantes para o estudo.

\section{Conhecendo a prática dos professores}

A pesquisa de campo se deu através de observações, num período de 2 meses, sendo realizadas de 5 a 7 visitas, com em média 2 horas semanais. Em cada escola observou-se a prática de um professor (a). 
Algumas turmas tiveram perda de uma ou duas visitas, tendo em vista que ocorreram alguns imprevistos, próprios do cotidiano escolar como: realização de Projeto de Leitura, Conselho de Classe, manutenção da infraestrutura do prédio escolar, licença por motivos familiares e ausência do professor.

A fim de conhecer mais de perto a prática do professor aplicou-se um questionário estruturado em 3 eixos, que serão descritos e analisados a seguir. A discussão apoia-se em autores que embasaram o início da pesquisa e em outros que foram sendo necessários ao longo da análise dos dados.

\section{Eixo I - Da identificação}

No eixo I as escolas A e B foram identificadas pelos professores quanto a estrutura física como regulares, enquanto a C e D consideradas muito boas. Quando perguntados a respeito do clima institucional os quatro professores classificaram suas escolas como tendo ambientes excelentes (A e D) ou amigáveis (B e C). Após revisão de literatura Pereira, Oliveira e Teixeira (2013, p. 5) definem o conceito de clima como "o conjunto de crenças, valores e atitudes que interagem entre os alunos, professores e administradores para definir os parâmetros de comportamento aceitável e normas para a escola”. Bastos (2019, p. 13), considera que "ao mesmo tempo em que o Clima Escolar é único a cada realidade, é um instrumento importante à reflexão quanto às formas possíveis da escola enxergar e rever suas práticas, as relações entre os sujeitos pertencentes, em busca de uma melhoria na qualidade da educação”. Com esta afirmativa, levanta uma questão importante no que se refere ao clima como um instrumento, para que cada escola se olhe dentro de suas particularidades.

Ao se comparar as considerações feitas pelos professores das escolas A e B, com relação à identificação como sendo "regulares", com o clima institucional "excelente e amigável”, viu-se que o clima institucional é superior às necessidades físicas da escola e da sala de aula. Portanto, a qualidade do ambiente foi uma categoria a qual observou-se que a equipe de gestão vem investindo, sem com isto, desconsiderarem a necessidade de continuarem lutando por melhorias na estrutura da escola.

Ainda, com base nas respostas relativas ao clima institucional, observou-se que este vem contribuindo para o resultado favorável nas avaliações do IDEB das escolas observadas. Considera-se importante destacar a temática do clima escolar, tendo em vista que já ocupa lugar nas discussões em torno da gestão democrática e em pesquisas institucionais. Apesar de não dever afirmar-se que uma escola com clima favorável, seja garantia de uma gestão democrática.

A pesquisa de clima organizacional é um instrumento que permite às organizações identificarem as tendências de satisfação ou insatisfação a partir de uma consulta a seus colaboradores. O clima organizacional é um ISSN 2526-2882 
instrumento eficaz que estabelece o elo entre o nível individual e o nível organizacional, levando-se em conta o que os indivíduos numa coletividade pensam a respeito do lugar em que trabalham (BISPO, 2006, apud PEREIRA, OLIVEIRA E TEIXEIRA, 2013, p. 3).

Compartilha-se com a ideia de que o conceito de clima institucional ou escolar passa por interpretações variadas de autor para autor e diversificadas definições. Para Bastos (2019, p. 32), apesar disso, "todas partilham um aspecto em comum: o clima escolar é o entendimento de todos os pertencentes a um mesmo ambiente escolar sobre as relações interpessoais entre todos os envolvidos neste nicho, bem como os processos de ensino e aprendizagem ali desenvolvidos".

Para alguns autores há aproximação entre o conceito de clima escolar e de cultura escolar, conforme posto por Pereira, Oliveira e Teixeira (2013, p.4), que atribuem a cada organização peculiaridades que são inerentes à sua própria maneira de organizar-se, tendo influência direta do lugar onde está inserida. Os autores ainda referenciam Griffith (1999) ao afirmar que "o clima da escola facilita as interações sociais e individuais, satisfazendo a identidade dos membros do grupo e necessidades interpessoais” [...]. Esses elementos emocionais e sociais vão interferir na dinâmica cotidiana, nas relações internas entre os funcionários, como também junto aos pais, responsáveis e comunidade do entorno.

A compreensão e avaliação do clima organizacional envolvem todos os acontecimentos diários, afazeres e momentos específicos que resultam na dinâmica final e generalizada da instituição. Desta dinâmica podem ser identificados padrões de acontecimentos corriqueiros e esporádicos. Toda esta dinâmica é construída por cada indivíduo participante da instituição, agregado aos seus comportamentos, sensações, atividades, poder de ação e desenvolvimento humano de cada indivíduo. (BASTOS, 2019, p.31)

Acredita-se fazer parte do clima institucional a presença dos pais e responsáveis na escola, conforme reafirmado pelos professores das escolas B, C e D. Considera-se relevante esta observação, demarcando a necessidade de se pensar estratégias para ampliação de "modelos" de gestão que alcancem tal objetivo. A troca de experiências entre os gestores das redes de ensino poderia ser um elemento importante para melhoria desta questão, tida como relevante para melhoria ou manutenção de um bom clima institucional. Retoma-se o conceito de habitus de Bourdieu (2009) para amparar a importância da vivência e experiência entre os pares e Grenfell (2018) a partir da ideia de "enigma experencial”. Além disso, acredita-se que análises de situações cotidianas realizadas coletivamente junto a gestores mais experientes, poderiam contribuir também com as escolas que enfrentam baixo desempenho. Outro aspecto que não deve ser desconsiderado, é a formação continuada do gestor, a fim de aperfeiçoar aspectos não só da gestão, mas também de sua relação junto à equipe. 
De acordo com o observado, o clima da escola, contido em um modelo de gestão bemsucedido, adicionado às questões reflexivas relativas ao currículo e a avaliação, interferirão no modelo de escola, tendo em vista que não são elementos isolados.

A partir do questionário aplicado constatou-se que os 04 professores que participaram da pesquisa têm nível superior. Além da escolarização, a vivência oriunda da prática, aqui conceituada como habitus, aparece também como agregadora na formação desses professores. Conforme perspectiva de Grenfell (2018, p. 78),

o habitus liga o social com o individual porque as experiências do curso da vida de uma pessoa podem ser únicas em termos de seu conteúdo particular, mas são compartilhadas em termos de sua estrutura com outras pessoas da mesma classe social, gênero, etnia, sexualidade, ocupação, nacionalidade, região $[\ldots]$

Isto se dá ao considerar que a professora tem um tempo de vivência que envolve o seu modo de agir, sentir, pensar, individualmente, a partir das interações sociais que a constituem, mas que são agregadoras de outros esquemas incorporados junto ao grupo de sua escola. Constata-se que "o individual, o pessoal e o subjetivo são simultaneamente sociais e coletivamente orquestrados" (SETTON, 2002, p. 63)

A professora da escola A traz como referência a experiência, visto que atuou como integradora e professora no laboratório de matemática e está na mesma unidade escolar há 12 anos, sendo sua primeira atuação no $5^{\circ}$ ano. Da mesma forma o professor da escola B, que está na escola há 10 anos, em grande parte atuando no $5^{\circ}$ ano, nos dois turnos. A professora da escola C está na mesma escola há 3 anos e atua no mesmo ano de escolaridade nos dois turnos. Na escola D a professora foi chamada especificamente para atuar no ano letivo de 2017, período de realização da pesquisa. Iniciou o trabalho em uma turma que já havia passado dois professores e que era caracterizada como uma turma "problema" para a escola. No período de observação, o registro da turma era de superação dos "problemas disciplinares", além de ser reconhecida como participativa em atividades extracurriculares. Durante uma das idas à escola observou-se uma bela exposição artística no corredor, realizada pela turma mencionada.

No que se refere aos professores das escolas A e B, observou-se que além da formação superior dos professores que ou já ingressaram em cursos de pós-graduação ou a concluíram, apresentam também um tempo de experiência em sala de aula de 05 anos em média, o que leva a pensar a respeito da importância da formação somada ao tempo de atuação na sala de aula como elementos que geram segurança ao docente. Para Azevedo e Alves (224, p. 9) "é nesse contexto - a do cotidiano escolar - que são forjados os docentes. Nele se aprende a ser professor, sendo professor".

O tempo de permanência na escola também pode alterar o resultado se cruzado com a referência feita ao clima institucional mencionado no eixo I, já que oportuniza a formação de ISSN 2526-2882

$$
\text { * } 397 *
$$


identidade junto à escola, à comunidade e o vínculo afetivo com a equipe de trabalho, interferindo positivamente nos resultados. Em revisão de literatura Pereira, Oliveira e Teixeira (2019, p.2) ressaltam "a importância de estudar clima e cultura nas organizações escolares pelo fato do clima escolar positivo ser reconhecido como um componente importante de escolas bem-sucedidas e eficazes [...]"

Ainda, com referência a prática cotidiana dos professores, com respeito às características das salas de aula, o quantitativo de alunos varia de 23 a 30 alunos. A escola A tem 28 alunos e a turma tem como característica uma certa inquietação, que levava a professora a várias interrupções ao longo da aula. Não se observou indisciplina fora do padrão normal para a faixa etária. Com fins de identificação, destaca-se que a escola está localizada em uma comunidade de baixo poder aquisitivo, os alunos, em sua maioria, são oriundos do próprio bairro. A turma conta com 01 aluno incluso, porém sem laudo.

Enquanto a escola B tem 30 alunos e a turma é relativamente tranquila, porém observou-se que o cansaço e o sono os deixam alheios à boa parte da aula. A turma era reconhecida na escola como "problemática", sem especificação de que tipo de problema se referem. Devido a isto optaram em não colocar nenhum aluno incluso na turma. A escola localiza-se em um bairro de baixo poder aquisitivo. Nem todos os alunos residem próximo à escola e sim em bairros periféricos.

A escola $\mathrm{C}$ tem 22 alunos e a turma observada apresenta um relacionamento próximo com a professora, que a mantém sempre produtiva, o que faz com que se movimente pela sala, interagindo com os alunos e eles com ela. Para Silva e Aranha (2005, p. 376) "É fato que o modo de ser do professor, seu jeito de pensar, agir e sentir repercutirá no comportamento dos alunos, bem como a imagem e a concepção que o aluno tem do professor irá interferir na ação do professor".

A escola C localiza-se em um bairro de poder aquisitivo médio, porém com questões de pobreza e violência em seu entorno. Os alunos matriculados, em sua maioria, residem em localidades adjacentes à escola. A turma conta com 01 aluno incluso, porém sem laudo.

Enquanto a escola D tem 23 alunos e a turma é tranquila e participativa. As dificuldades com as repetidas trocas de professor foram sanadas com a chegada da professora participante da pesquisa. Localiza-se em um bairro de alto poder aquisitivo. os alunos em sua maioria moram em bairros periféricos, apesar de alguns terem vindo de escolas particulares. A turma conta com 04 alunos inclusos, sendo 02 com laudo, 01 síndrome de down e 01 sem laudo, com baixa frequência. Assim como a professora da escola C, movimenta-se pela sala, interagindo com os alunos e propondo atividades criativas, que mantém o grupo produtivo. Apesar da complexidade que envolve o cotidiano de uma sala de aula que conta com alunos inclusos, para Silva e Aranha (2005, p. 376) “A construção de uma sociedade inclusiva é de 
fundamental importância para o desenvolvimento e a manutenção de um estado democrático”. Portanto, a escola tem papel fundamental nessa formação.

As escolas observadas estão localizadas em bairros diferentes, com características próprias, com quadro econômico e social distinto. A escola C que garante a maior nota do IDEB dentre as quatro escolas observadas, tem 8 alunos a menos na sala de aula, se comparada com a escola B. Este é um aspecto que favorece ao professor da escola C, porém leva-se em consideração a existência de o1 aluno que chegou ao $5^{0}$ ano sem estar alfabetizado. Nesta turma, em particular, chamou atenção durante uma das observações, a metodologia dialógica da professora junto aos alunos e a valorização dada aos questionamentos dos alunos, instigando-os à reflexão.

Para o educador-educando, dialógico, problematizador, o conteúdo programático da educação não é uma doação ou uma imposição, um conjunto de ideias a ser depositado nos educandos, mas a devolução organizada, sistematizada e acrescentada ao povo daqueles elementos que este lhe entregou de forma desestruturada. (FREIRE, 2005).

Independentemente da localização das escolas, considera-se a metodologia dialógica um instrumento de aproximação entre professor e aluno, que pode favorecer positivamente o resultado da turma. Considera-se que a observação da turma e dos alunos em suas especificidades pode ser aprimorada ao desenvolver-se um olhar mais investigativo dentro da sala de aula.

Outro fator considerado como um diferencial trazido pela escola $\mathrm{C}$, foi o interesse das crianças durante a aula, o que fez com que não pedissem para ir ao banheiro ou beber água (comum nas escolas) durante quase todo o tempo em que se esteve na sala. Em análise considerou-se essas saidinhas da sala como "rotas de fuga", que podem ser observadas, questionadas e auto avaliadas nas escolas como passível de reflexão. Acredita-se que a forma como o professor da escola $\mathrm{C}$ conduz a turma foi o diferencial dentre as outras turmas observadas.

\section{Eixo II - Da Didática e Metodologia na sala de aula}

No eixo II todos os professores marcaram como opção o uso do quadro branco, livro didático e jogos pedagógicos. Destaca-se as escolas C e D que disseram utilizar maquetes, vídeos, brincadeiras de infância, artes e literatura de cordel, o que foi confirmado durante as observações. Neste caso, cabe ressaltar novamente o quantitativo de alunos por turma, que pode favorecer a utilização de uma metodologia mais dinâmica e interativa.

Enquanto a escola B, afirmou utilizar jogos pedagógicos, porém durante as observações não se identificou este uso. O jogo tem a função de organização de conceitos como: noção espacial, regras, resolução de problemas, socialização e outros. Mesmo estando no $5^{0}$ 
ano acredita-se que a utilização desse recurso e de metodologias variadas, favorece a construção de conhecimentos, inclusive matemáticos. Para Smole, Diniz e Cândido (2007, p. 12) "o jogo na escola foi muitas vezes negligenciado por ser visto como uma atividade de descanso ou apenas como um passatempo". O uso de materiais que possibilitem a manipulação por parte dos alunos auxilia na formação de conceitos e fechamentos de lacunas que ainda se encontram abertas em alguns alunos, mesmo nos $5^{\circ} \mathrm{s}$ anos.

Especificamente em uma das observações, acompanhou-se a correção de alguns exercícios da Prova Brasil que mencionavam a utilização do material dourado, o professor fez menção, desenhou, porém não mostrou o material ou disponibilizou aos alunos para que estes pudessem manipular e compreender melhor os valores atribuídos às peças. Kamii (2007) e Castorina; Ferreiro; Lerner; Oliveira, (1998) acreditam, com base em Piaget, que para o conhecimento se dar é preciso fazer relação com o objeto, estabelecendo as diferentes funções deste objeto, coordenando relações entre os objetos.

\section{Eixo III - Da Avaliação e mediação da aprendizagem}

$\mathrm{Na}$ análise do Eixo III do questionário constatou-se que as 04 escolas trabalham num mesmo formato avaliativo: Prova bimestral; Trabalhos individuais e em grupo e Testes. As escolas B e C aplicam simulados. A realização de tarefas de casa se dá todos os dias em todas as escolas.

Quanto ao processo de intervenção junto aos alunos com dificuldades de aprendizagem, detectou-se quatro tipos de trabalhos com as crianças: Escola A - Reforço no contra turno; Escola B - Encaminhamento para a sala de recursos; Escola C - Atividade diferenciada com um aluno que chegou sem estar alfabetizado; Escola D - Atividade uma vez por semana com a professora da turma. Além dos encaminhamentos próprios de cada escola, todas as crianças frequentam um espaço disponibilizado pelo município para atendimento com equipe multidisciplinar. Constata-se ao relacionar os índices positivos do IDEB das 4 escolas, que a mediação da aprendizagem, ainda que com formatos diferentes, e, o encaminhamento de tarefas de casa, são elementos importantes e podem ter relevância nos resultados.

\section{Considerações finais}

Ao longo desse estudo, além do objetivo já estabelecido inicialmente, uma questão emergiu e perdurou. Que lugar a avaliação ocupa na escola e na prática dos professores? Com o olhar voltado para a prática avaliativa dos professores percebeu-se que apesar de serem observadas quatro escolas com "bons resultados", ou de "boa qualidade", na perspectiva dos índices e metas propostas, inquietou-se perceber numa mesma rede de ensino que, ora a avaliação ocupou lugar de centralidade, ora fez parte do processo ensino aprendizagem. Olhando nesta direção, contribuir-se-ia repensar esses lugares, tendo em vista que as escolas 
e/ou os professores que a colocaram a avaliação como central comprometeram a qualidade da aula, de acordo com o que apontou os dados das observações. Isto foi reafirmado nas duas escolas - A e B, que têm a metodologia da aula voltada para a utilização de atividades similares as da Prova Brasil como "treinos" para se alcançar "bons" resultados, portanto repetem uma relação tradicional de ensino aprendizagem, negativa, pois não contextualizam, não instigam a curiosidade e reflexão dos alunos. Com isto, teme-se que na continuidade dos estudos isso possa desfavorecer a construção de conhecimento, de autonomia, senso crítico e coletividade dos alunos. Pode-se ainda, suscitar um questionamento acerca do que foi "aprendido" nos momentos de treino, se houve realmente um processo de apreensão de conhecimento ou apenas de memorização.

Enquanto as outras duas escolas - C e D, colocam a avaliação dentro do processo, trabalham o proposto oficialmente, porém não utilizam uma metodologia de trabalho voltada para a memorização e o treino. Há bom aproveitamento nas aulas e a relação dos professores com os alunos são mais interessantes, possibilitando que as crianças vivam outras experiências. Essas escolas ouvem o mesmo discurso oficial, porém o redimensionam no contexto da prática. O que mostra que é possível chegar aos "bons" resultados, sem necessariamente trabalhar apenas através de treinos. Observou-se a aplicação de atividades de música e artes, que contribuem com a construção de outros valores, habilidades e competências. Além de promover a socialização, aspecto fundamental para que o aluno permaneça na escola, crie vínculos afetivos e aprenda significativamente.

Referindo-se a metodologia, destaca-se o trabalho diferenciado de uma professora, junto a um aluno não alfabetizado. Mostrou através da diversificação de ações, com objetivos e critérios bem definidos, a abertura de possibilidades de trabalhos mais eficientes. A metodologia do trabalho em grupo, objetivado e realizado didaticamente de forma consciente, valorizando a subjetividade do aluno. Olhar o grupo, sem perder de vista as particularidades dos alunos e construir com estes a ideia de coletividade e participação. A prática observada na escola $\mathrm{C}$ contribuiu com a investigação, no que se refere a mediação do professor junto aos alunos, trazendo elementos importantes para uma metodologia interventiva.

Além disso, considera-se relevante destacar, que se a avaliação não for repensada no contexto da discussão aqui apresentada, ficará faltando um elemento no pilar aqui estabelecido, avaliação - metodologia - formação. Questões de fundamentos e até mesmo de cultura precisam ser revisitados, tendo em vista que a avaliação vem sendo objeto de elaborações nas mais variadas correntes pedagógicas, entretanto pouco tem se visto de alteração na prática da sala de aula. Mesmo entre as 4 professoras das escolas envolvidas na pesquisa não houve congruência de todos os aspectos. As metodologias são diferentes e as práticas avaliativas também, portanto há espaço para troca de vivências/experiências. 
Outro aspecto resultante da pesquisa de campo refere-se ao conceito de "clima escolar", que é considerado um elemento importante na gestão da escola, que tem como premissa um trabalho de qualidade. Entretanto, não se deve desconsiderar que apesar de um conceito importante e agregador da gestão democrática, precisa desenvolver categorias de análises inerentes a cada espaço escolar, tendo em vista que são únicos.

Retomando a perspectiva desse artigo em contribuir com a elaboração de políticas públicas para a formação docente, conclui-se sem fechamento das reflexões, de que é preciso ouvir os professores acerca de suas necessidades cotidianas, a fim de se pensar junto de que maneira a formação continuada pode auxiliar mais efetivamente na resolução dos problemas inerentes à sala de aula.

Espera-se com os elementos apontados nessa pesquisa, contribuir para a elaboração de políticas de formação continuada do professor que ultrapasse planos governamentais. Além de trazer considerações para o real lugar que a avaliação tem na produção do conhecimento, tendo em vista a interlocução com a prática da sala de aula e sua realidade.

\section{Referências}

AZEVEDO, J. G. de; ALVES, N. G. A. (orgs). Formação de professores: possibilidades do imprevisível. $1^{\text {a }}$ ed. Rio de Janeiro: DP\&A, 2004. p. 120.

BASTOS, C. Z. A. Clima escolar: estudo de caso em uma escola democrática do estado de São Paulo. 2019. 99 f. Tese de Doutorado em Educação. Faculdade de Filosofia e Ciências, Universidade Estadual Paulista (Unesp). Marília, 2019.

BOURDIEU, P. Coisas Ditas. $1^{\mathrm{a}}$ ed. São Paulo: Braziliense, 2003. p. 234.

. O Poder Simbólico. $16^{\mathrm{a}}$ ed. Bertrand: Brasil, 2009. p. 322.

CASTORINA, José Antonio; FERREIRO, Emília; LERNER, Délia; OLIVEIRA, Marta Kol. Piaget e Vygotsky: novas contribuições para o debate. $2^{\mathrm{a}}$ ed. São Paulo: Ática, 1998. p. 175.

FREIRE, P. Pedagogia do Oprimido. $1^{\mathrm{a}}$ ed. Rio de Janeiro: Paz e Terra, 2005. p. 213.

GRENFELL, M. Pierre Bourdieu: Conceitos fundamentais. $1^{\mathrm{a}}$ ed. Petrópolis: vozes, 2018. p. 393.

KAMII, Constance. A criança e o número. $8^{a}$ ed. Campinas: Papirus, 1988. p. 124.

MACHADO, C. e ALAVARSE, O. M. Avaliação interna no contexto das avaliações externas: desafios para a gestão escolar. A Revista Brasileira de Política e Administração da Educação, v. 30, n. 1, pp. 63-78, jan/abr. 2014.

MOSS, G. A Strategy for differentiation. Birmingham: Questions Publishing, 1996.

PEREIRA, F. A. M.; OLIVEIRA, E. de; TEIXEIRA, J. C. M. A Influência do clima e cultura organizacional na gestão de uma escola do ensino fundamental. Qualit@s Revista Eletrônica. v. 14, n. 1, pp. 1-16. 2013.

ISSN 2526-2882 
SMOLE, K. S.; DINIZ, M. I.; CÂNDIDO, P. Jogos de matemática de $1^{\circ}$ a $5^{\mathbf{o}}$ ano. $1^{\mathrm{a}}$ ed. Porto Alegre: Artmed, 2007.

SETTON, M. G. J. A teoria do habitus em Pierre Bourdieu: uma leitura contemporânea. Revista Brasileira de Educação, Rio de Janeiro, n. 20, pp. 60-70, Ago. 2002. Disponível em <http://www.scielo.br/pdf/rbedu/n20/n20a05.pdf>. Acesso em: maio, 2017.

SILVA, S. C.; ARANHA, M. S. F. Interação entre professora e alunos em salas de aula com proposta pedagógica de educação inclusiva. Revista Brasileira de Educação Especial, Marília, v. 11, n. 3, pp. 373-394, Dec. 2005. Disponível em < http://www.scielo.br/pdf/rbee/v11n3/v11n3a05.pdf>. Acesso em: junho, 2017.

TARDIF, M. Saberes profissionais dos professores e conhecimentos universitários Elementos para uma epistemologia da prática profissional dos professores e suas consequências em relação à formação para o magistério. Revista Brasileira, $\mathrm{n}^{0} \quad 13$, Jan/Fev/Mar/abr. 2000.

TARDIF, M. Saberes Profissionais dos Professores e Conhecimentos Universitários: elementos para uma epistemologia da prática profissional dos professores e suas consequências em relação à formação para o magistério. Revista Brasileira de Educação. ANPED, São Paulo, n. 13, pp. 5-24, jan./abr. 2000. Disponível em: < http://anped.tempsite.ws/novo_portal/rbe/rbedigital/RBDE13/RBDE13_05_MAU RICE_TARDIF.pdf >. Acesso em: maio, 2017.

TURA, Maria de Lourdes Rangel. A observação do cotidiano escolar. In: ZAGO, Nadir. CARVALHO, Marília. VILELA, Rita (orgs). Itinerários de pesquisa. Perspectivas qualitativas em Sociologia da Educação. $1^{\text {a }}$ ed. Rio de Janeiro: DP\&A, 2003. p. 309.

ZAGO, Nadir; CARVAlHO, Marília Pinto de; VILELA, Rita Amélia Teixeira (Orgs). Itinerários de pesquisa. Perspectivas qualitativas em Sociologia da Educação. $1^{\mathrm{a}}$ ed. Rio de Janeiro: DP\&A, 2003. p. 309.

\section{Biografia Resumida}

Cremilda Barreto Couto: Pedagoga pela Faculdade de Filosofia ciência e Letras de Macaé (1988), mestre em Educação pela Pontifícia Universidade Católica do Rio de Janeiro (2008) e doutora em Educação pela Universidade Federal Fluminense (2014). Pós-doutora pela UFF/RJ (2019). Participa do Núcleo de Estudos e Pesquisas em Gestão e Políticas Públicas - NUGEPPE. 
Professora com vínculo contratual com a Faculdade Professor Miguel Ângelo da Silva Santos, professor da Faculdade de Filosofia ciência e Letras de Macaé, atuando principalmente nos seguintes temas: Política Pública. Formação docente. Currículo e Avaliação.

Lattes: http://lattes.cnpq.br/2673954351876231

Contato: cremildabcouto@gmail.com 